\title{
船測無線方位の計算図装（共線図表）について
}

\section{On the Nomogram of Determing the Position Line of a Ship with Radio Bearing Conversion.}

\author{
藤 崎 正治（海 保 大）
}

\begin{abstract}
When a ship receives an electric wave issued from a radio station, we can determine the position line of the ship by its direction. For the purpose to determine this, an intersection chart has teen published from the Hydrographic Department of Maritime Safety Agency. To avoid the disadvantage arising from the intersection chart, I tried to determine the position line by the nomogram.

The determing, equation is :

$$
\sin L \cot \alpha=\cos l \tan l_{0}-\sin l \cos L
$$

Where $\alpha$ is the azimuth of the radio station from the ship, $l_{0}$ is the latitude of the station, $l$ is the latitude of the ship, and $L$ is the difference of the longitude between the ship and the station. In this case $\alpha$ and $l_{0}$ are known, $l$ and $L$ are unknown.

Fig. 2 and Fig. 3 make a pair of nomogram. Method of application

In Fig. 2, marke the point of the value of $\alpha$ lying on the line $\cot \alpha$. Draw the straight line $m$ passing through the point $\alpha$. The line $m$ and the line $x$ intersect on the point $A$. The line $m$ and the line tan $l_{0}$ intersect on the point $B$. Mark the point $C$ of the value of $l_{0}$ lying on the line tan $l_{0}$. The segment $B C$ is the value of $|y|$.

In Fig. 3, mark the point $D$ of the value $A$ lying on the line $x$, and the point $E$ of the value $|y|$ lying on the line $y$ in the direction upward from $O$.

The point $F$ that intersects with the line $D E$ and the curve $l$ is the value of the latitude, say $l$. Mark the point $G$ of the value $|y|$ lying on the line $y$ in the direction downward from $O$. The point $H$ that intersects with the line $D G$ and the curve $L$ is the value of the difference of the longitude.

Add the value $H$ to the station's longitude or subtract the value $H$ from the station's longitude. That is the value of the longitude, say $L$.

Plot the several points $(l, L)$ on the chart, and the line that goes through these points is the line of position.

For another radio station, we can get another line of position.

The point on which two lines intersect is the position of the ship.
\end{abstract}


陸上局で発しを無線電波の方问を船から惻蛋し之を利用して船位を定めるには次の公式があり ます。船から測定しを陸上局の方位角を $\alpha$ とし，船及路上局の緯度を夫々 $l$ ． $l_{0}$ 両者の経度美 を $L$ とすると球面三角形の公式から次の式を得亦。

$\cos a \sin \alpha=\cos l_{0} \sin L$

$\cos a \cos \alpha=\sin l_{0} \cos l-\cos l_{0} \sin l \cos L$

$a$ を消去すると

$$
\sin L \cot \alpha=\cos l \tan l_{0}-\sin l \cos L
$$

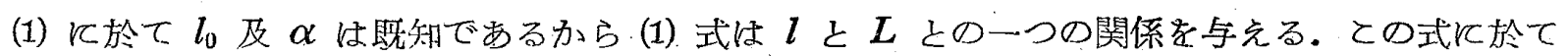
$x=\sec l \sin L, \quad y=\tan l \cos L$

と衫け壮

$$
\cot \alpha=\frac{\tan l_{0}-\tan l \cos L}{\sec l \cdot \sin L}=\frac{\tan l_{0}-y}{x}=\frac{Y}{x}
$$

(2) ๖り

$$
\begin{aligned}
& \frac{x^{2}}{\sec ^{2} l}+\frac{y^{2}}{\tan ^{2} l}=1 \\
& \frac{y^{2}}{\sin ^{2} \bar{L}^{-}}-\frac{y^{2}}{\cos ^{2} L}=1
\end{aligned}
$$

（4）及 (5)の共点図表は海上保安朾水路部より発行され航海者に利用されていすすが Fig. 4 の如

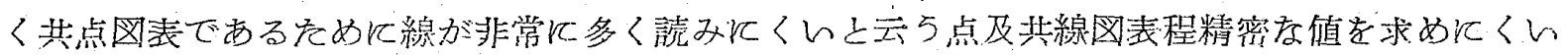
と云ら尔がありますので次のよらね一組の共線

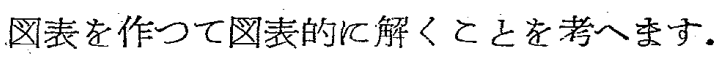

佮 $0 \leqq l \leqq 60^{\circ}$ とすれば.

$$
\begin{aligned}
& 0 \leqq x \leqq 2.000 \\
& 0 \leqq|y|<1.733 .
\end{aligned}
$$

(3) の共線図表を作るため (3) を次の如く書きすす

$$
\begin{gathered}
\left|\begin{array}{ccc}
1 & 0 & -m \cot \alpha \\
0 & 1 & \left.n \tan l_{0}-y\right) \\
\frac{x}{m} & \frac{1}{n} & 0
\end{array}\right|=0 \\
m=n=1 \text { ŁLて } \\
\xi=\cot \alpha \\
\eta=-\left(\tan l_{0}-y=-Y\right. \\
\xi x+\eta=0
\end{gathered}
$$

即二本の支持線は平行な直線，一本の支持線は之 と交る值線となります。第三の值線は基線上 $S=\frac{1-x}{1+x} d$ となり委すから

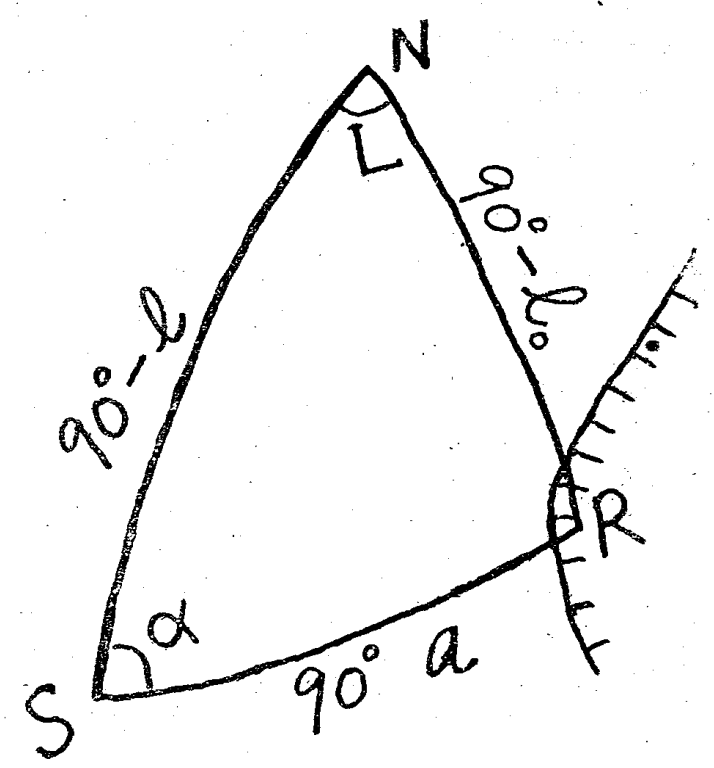

Fig: 1

\begin{tabular}{|c|c||c|c|c|c||c|c|}
\hline$x$ & $\frac{1-x}{1+x} d$ & $x$ & $\frac{1-x}{1+x} d$ & $x$ & $\frac{1-x}{1+x} d$ & $x$ & $\frac{1-x}{1+x} d$ \\
\hline 0.0 & $1.000 d$ & 0.4 & $0.429 d$ & 0.8 & $0.111 d$ & 1.4 & $-0.167 d$ \\
0.1 & 0.818 & 0.5 & 0.333 & 0.9 & 0.053 & 1.6 & -0.231 \\
0.2 & 0.667 & 0.6 & 0.250 & 1.0 & 0.000 & 1.8 & -0.286 \\
0.3 & 0.538 & 0.7 & 0.176 & 1.2 & -0.091 & 2.0 & -0.333 \\
\hline
\end{tabular}




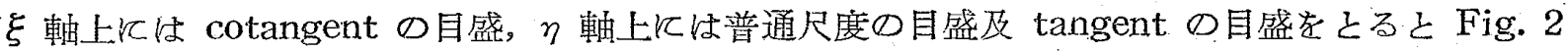
の如くなります。

（4）の共線図表作るをめ

$$
x^{2}+y^{2} \operatorname{cosec}^{2} l=\sec ^{2} l
$$

$$
\left|\begin{array}{ccc}
1 & 0 & -m x^{2} \\
0 & 1 & -n y^{2} \\
\frac{1}{m} & \frac{1}{n} \operatorname{cosec}^{2} l-\sec ^{2} l
\end{array}\right|=0
$$

$m=n=1$ と初を

$$
\begin{aligned}
& \xi=x^{2} \\
& \eta=y^{2} \\
& \xi+\eta \operatorname{cosec}^{2} l=\sec ^{2} l
\end{aligned}
$$

(6) を共線図表で書くために点座標であらわせば

$$
\begin{aligned}
& X=-\frac{1-\operatorname{cosec}^{2} l}{1+\operatorname{cosec}^{2} l} d=\frac{1+\cos 2 l}{3-\cos 2 l} d \\
& Y=\frac{\sec ^{2} l}{1+\operatorname{cosec}^{2} l}=\frac{2 \tan ^{2} l}{3-\cos 2 l}
\end{aligned}
$$

但 $b$ 任任意常数.

$l$ は普通 $60^{\circ}$ 上り高緯度は必要なんから $60^{\circ}$ 迄にしておきます。

\begin{tabular}{|c|c|c|c|c|c|c|}
\hline$l$ & $\cos 2 l$ & $1+\cos 2 l$ & $3-\cos 2 l$ & $2 \tan ^{2} l$ & $\frac{1+\cos 2 l}{3-\cos 2 l}$ & $\frac{2 \tan ^{2} l}{3-\cos 2 l}$ \\
\hline $0^{\circ}$ & 1.0000 & 2.0000 & 2.0000 & 0.0000 & 1.000 & 0.000 \\
$5^{\circ}$ & 0.9848 & 1.9848 & 2.0152 & 0.0154 & 0.985 & 0.008 \\
$10^{\circ}$ & 0.9397 & 1.9397 & 2.0603 & 0.0622 & 0.941 & 0.030 \\
$15^{\circ}$ & 0.8660 & 1.8660 & 2.1340 & 0.1436 & 0.874 & 0.067 \\
$20^{\circ}$ & 0.7660 & 1.7660 & 2.2340 & 0.2650 & 0.791 & 0.119 \\
$25^{\circ}$ & 0.6428 & 1.6428 & 2.3572 & 0.4348 & 0.697 & 0.184 \\
$30^{\circ}$ & 0.5000 & 1.5000 & 2.5000 & 0.6668 & 0.600 & 0.267 \\
$35^{\circ}$ & 0.3420 & 1.3420 & 2.6580 & 0.9806 & 0.505 & 0.369 \\
$40^{\circ}$ & 0.1737 & 1.1737 & 2.8263 & 1.4082 & 0.415 & 0.498 \\
$45^{\circ}$ & 0.0000 & 1.0000 & 3.0000 & 2.0000 & 0.333 & 0.667 \\
$50^{\circ}$ & -.1737 & .0 .8263 & 3.1737 & 2.8408 & 0.260 & 0.895 \\
$55^{\circ}$ & -.3420 & 0.6580 & 3.3420 & 4.0796 & 0.197 & 1.221 \\
$60^{\circ}$ & -.5000 & 0.5000 & 3.5000 & 6.0004 & 0.143 & 1.714 \\
\hline
\end{tabular}

（5）を共線図表で畫くをめ

$$
\begin{aligned}
& \frac{x^{2}}{\sin ^{2} L}-\frac{y^{2}}{\cos ^{2} L}=1 \\
& x^{2}-y^{2} \tan ^{2} L=\sin ^{2} L \\
& \left|\begin{array}{ccc}
1 & 0 & -m x^{2} \\
0 & 1 & n y^{2} \\
\frac{1}{m} & \frac{\tan ^{2} L}{n}-\sin ^{2} L
\end{array}\right|=0
\end{aligned}
$$

$m=n=1$ と尔き 


$$
\begin{aligned}
& \xi=x^{2} \\
& \eta=-y^{2} \\
& \xi+\eta \tan ^{2} L=\sin ^{2} L
\end{aligned}
$$

（7）を共線図表でかくをめと点座標であらわせば

$$
\begin{aligned}
& X=\frac{\tan ^{2} L-1}{1+\tan ^{2} L} d=\left(1-2 \cos ^{2} L\right) d \\
& Y=\frac{\sin ^{2} L}{1+\tan ^{2} L}=\frac{1}{4} \sin ^{2} 2 L
\end{aligned}
$$

(7a) の $d$ を(6a) のd と同一にとる.

\begin{tabular}{|r|r|r|r|r|r|}
\hline$L$ & $\cos ^{2} L$ & $1-2 \cos ^{2} L$ & $\sin 2 L$ & $\sin ^{2} 2 L$ & $\frac{1}{4} \sin ^{2} 2 L$ \\
\hline $0^{\circ}$ & 1.0000 & -1.0000 & 0.0000 & 0.0000 & 0.0000 \\
$5^{\circ}$ & 0.9924 & -.9848 & 0.1736 & 0.0301 & 0.0075 \\
$10^{\circ}$ & 0.9698 & -.9396 & 0.3420 & 0.1170 & 0.0293 \\
$15^{\circ}$ & 0.9330 & -.8660 & 0.5000 & 0.2500 & 0.0625 \\
$20^{\circ}$ & 0.8804 & -.7608 & 0.6428 & 0.4132 & 0.1033 \\
$25^{\circ}$ & 0.8214 & -.6428 & 0.7660 & 0.5868 & 0.1467 \\
$30^{\circ}$ & 0.7500 & -.5000 & 0.8660 & 0.7500 & 0.1875 \\
$35^{\circ}$ & 0.6711 & .3422 & 0.9397 & 0.8830 & 0.2208 \\
$40^{\circ}$ & 0.5868 & -.1736 & 0.9848 & 0.9698 & 0.2425 \\
$45^{\circ}$ & 0.5000 & 0.0000 & 1.0000 & 1.0000 & 0.2500 \\
$50^{\circ}$ & 0.4132 & 0.1736 & 0.9848 & 0.9698 & 0.2425 \\
$55^{\circ}$ & 0.3290 & 0.3422 & 0.9397 & 0.8830 & 0.2208 \\
$60^{\circ}$ & 0.2500 & 0.5000 & 0.8660 & 0.7500 & 0.1875 \\
$65^{\circ}$ & 0.1786 & 0.6428 & 0.7660 & 0.5868 & 0.1467 \\
$70^{\circ}$ & 0.1170 & 0.7660 & 0.6428 & 0.4132 & 0.1033 \\
$75^{\circ}$ & 0.0670 & 0.8660 & 0.5000 & 0.2500 & 0.0625 \\
$80^{\circ}$ & 0.0301 & 0.9398 & 0.3420 & 0.1170 & 0.0293 \\
$85^{\circ}$ & 0.0076 & 0.9848 & 0.1736 & 0.0301 & 0.0075 \\
$90^{\circ}$ & 0.0000 & 1.0000 & 0.0000 & 0.0000 & 0.0000 \\
$95^{\circ}$ & & 0.9848 & & & 0.0075 \\
$100^{\circ}$ & & 0.9398 & & & 0.0293 \\
等 & & & & & \\
\hline
\end{tabular}
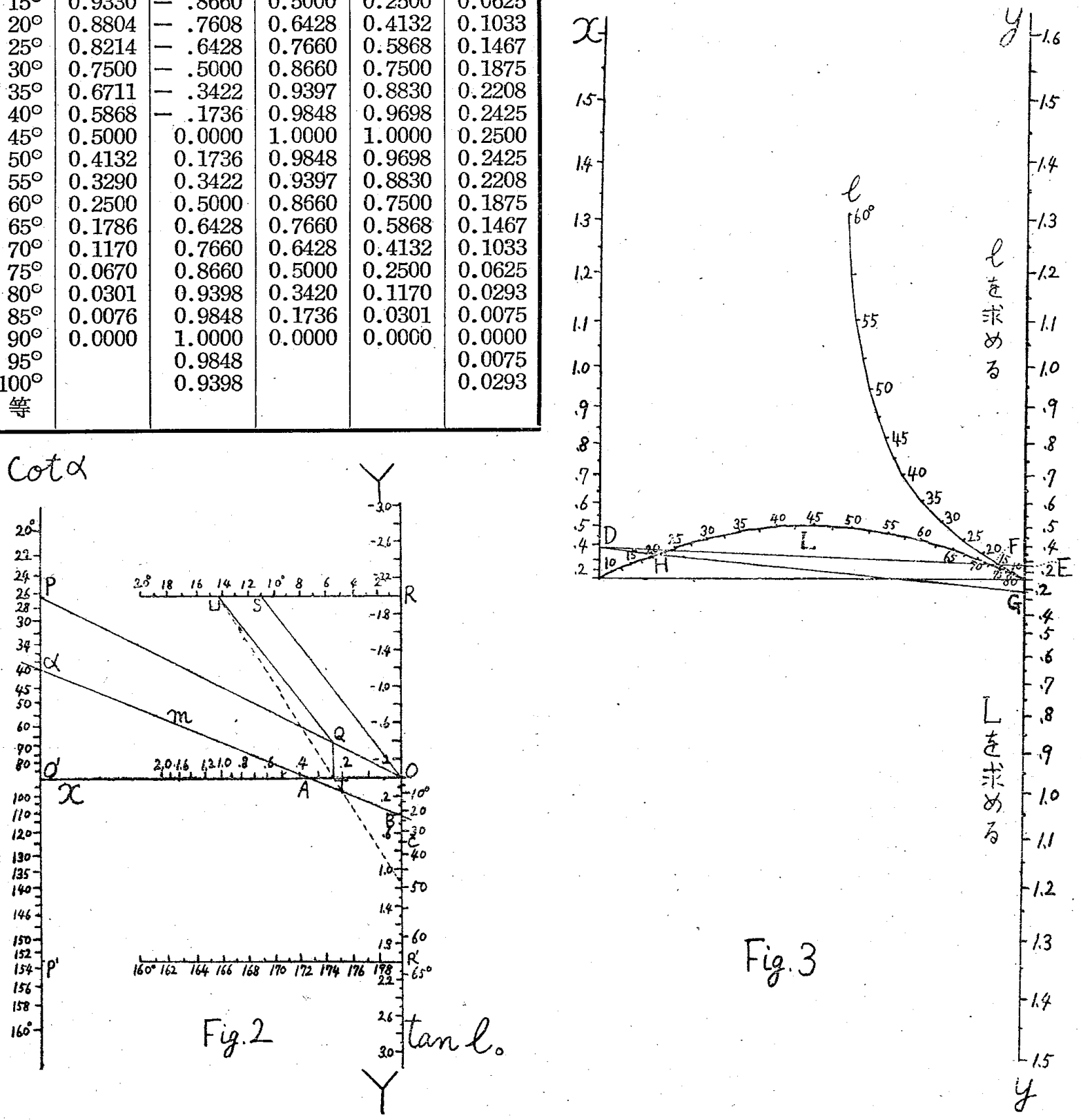
本図表の使用法

Fig. 2 飞於て $\cot \alpha$ 直線上飞測得方位角 $\alpha$ と $b$ ，点 $\alpha$ を過る直線 $m$ を引を直線 $x$ との 交点を $A$, 直線 $\tan l_{0}$ (即 $Y$ 直線) 亡の交点を $B$ 亡方. $\tan l_{0}$ 直線上飞陸上局の緯度 $l_{0}$ K

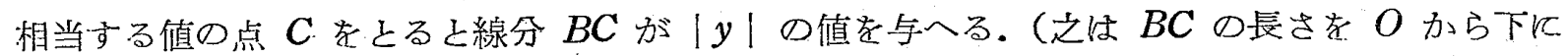
移し $Y$ 尺上の目盛読めば容易にわかります).

Fig. 3 飞於て $x$ 直線上飞 $A$ の値の点 $D$ をと点 $O$ 上り上方に $|y|$ の值の点 $E$ をとり曲 線 $l$ と $D E$ 直線との交点 $F$ の值が緯度となり，Oょり，下方に $|y|$ の值の点 $G$ をとり曲

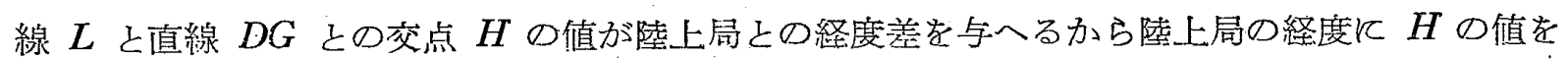
加減すると亡に上つて対応する経度がわかりま。，ての得られを緯度，経度を夫及 $l, L$ とする 之結局 $\alpha$ が決委る之無数の $(l, L)$ のの組が得られるととになりまず，実際には $(l, L) の$ 大体の值はわかつているからその近くになるよらを $(l, L)$ を与へる $(x, y)$ の組を決め一そ れは Fig. 3 亿於て $l$ 尺 $L$ 尺上に $l, L$ の近似值をとり， $x$ 上の点とそ机等二点学結ぶ直線が

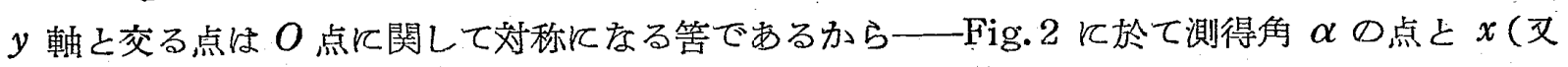

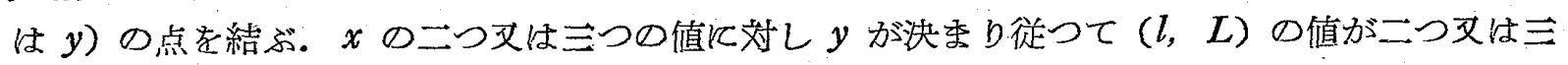
つ決まる，それ等の点を海図上飞記しそれらの点を結んで位置の線を出しすす，同様のととを别 の陸上局につんても行ん別の位置の線を出し禹位置の線の交点しして船位を決めることが出来を 于.

浒し Fig. 2 亿於て $\alpha<20^{\circ}$ 或は $\alpha>160^{\circ}$ 。場合には $R P$ (妆は $R^{\prime} P^{\prime}$ ) 上の度盛の点之 $O$ 点

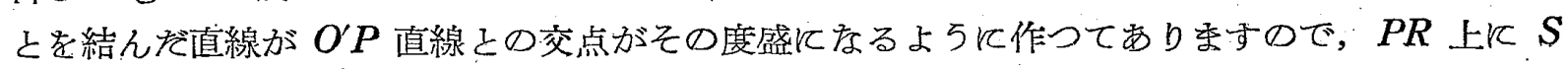
点をとり，OO'上飞 $T$ 点をとつをとすれば

\section{$T Q / / O^{\prime} P / / O R$ \\ $Q U / / O S$}

なる点 $U$ と $T$ 点を結ぶ直線が $Y$ 尺との交点が上の説明に於ける $B$ 点になりをす。 份在 $d=2, O R=2$ としたとをの $R P$ 上の目盛柱 $R S=8 \tan \alpha$ となりますから $R P$ 上の目 盛は次のよらになり委す。

\begin{tabular}{|c|c||c|c||c|c||c|c|}
\hline$\alpha$ & $8 \tan \alpha$ & $\alpha$ & $8 \tan \alpha$ & $\alpha$ & $8 \tan \alpha$ & $\alpha$ & $8 \tan \alpha$ \\
\hline $20^{\circ}$ & 2.912 & $15^{\circ}$ & 2.143 & $10^{\circ}$ & 1.410 & $5^{\circ}$ & 0.700 \\
$19^{\circ}$ & 2.754 & $14^{\circ}$ & 1.995 & $9^{\circ}$ & 1.267 & $4^{\circ}$ & 0.559 \\
$18^{\circ}$ & 2.599 & $13^{\circ}$ & 1.847 & $8^{\circ}$ & 1.124 & $3^{\circ}$ & 0.419 \\
$17^{\circ}$ & 2.446 & $12^{\circ}$ & 1.701 & $7^{\circ}$ & 0.982 & $2^{\circ}$ & 0.279 \\
$16^{\circ}$ & 2.294 & $11^{\circ}$ & 1.555 & $6^{\circ}$ & 0.841 & $1^{\circ}$ & 0.140 \\
\hline
\end{tabular}

[例 題]

\begin{tabular}{|crrrrrrc|}
\hline$l_{\mathbf{0}}$ & $\alpha$ & $x$ & のとき & $Y$ & $|y|=\left|\tan l_{0}-Y\right|$ & $l$ & $H$ \\
\hline $35^{\circ}$ & $40^{\circ}$ & 0.38 & 0.45 & 0.25 & $15^{\circ} 0^{\prime}$ & $21^{\circ} 10^{\prime}$ \\
$45^{\circ}$ & $110^{\circ}$ & 0.50 & -0.19 & 1.19 & $51^{\circ} 15^{\prime}$ & $17^{\circ} 50^{\prime}$ \\
\hline
\end{tabular}

実際には Fig. 2 及 Fig. 3 の二倍の大をさの図を作り之を用いて值を出します.

参考のため水路部発行の共点図表の一部を写したものをFig..4 としますが，使用法及全园は

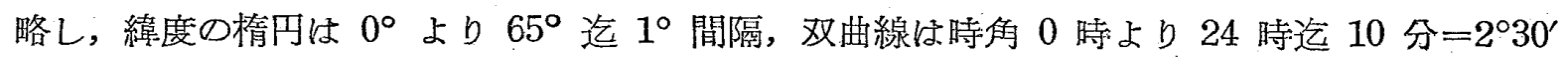
間隔のものを夫々 $5^{\circ}$ 間隔及 20 分間隔で写した.ものです。 


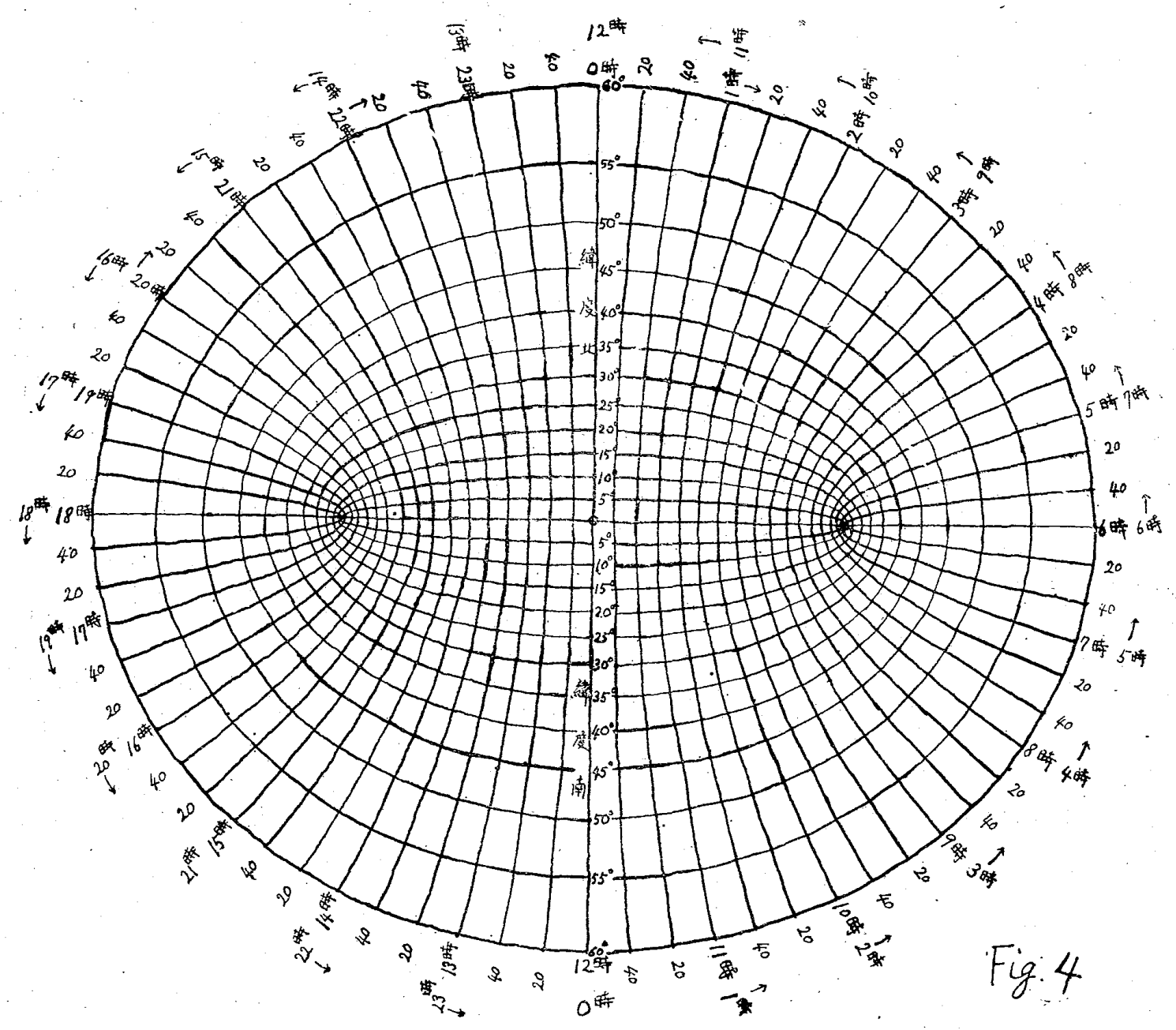

